\title{
"Amicus curiae": democratização e legitimação do processo decisório de controle da constitucionalidade
}

\author{
Bruno Rabelo Moreno ${ }^{1}$ \\ Márcia Regina Pitta Lopes Aquino ${ }^{2}$
}

\begin{abstract}
Resumo
Pesquisa teórica e jurisprudencial com o objetivo de analisar a possibilidade de intervenção de amicus curiae no processo de controle da constitucionalidade. Apresenta as formas de controle da constitucionalidade no direito brasileiro e as alterações e regulamentações legislativas ocorridas após a promulgação da constituição federal vigente. Expõe a compreensão doutrinária e jurisprudencial a respeito da figura do amicus curiae. Busca demonstrar que a intervenção do amicus curiae nos processos de controle da constitucionalidade, inclusive por via de exceção, pode contribuir para democratização e legitimação das decisões naqueles processos.
\end{abstract}

Palavras-Chave: Controle da constitucionalidade; Amicus Curiae; Procedimentos; Legitimação; Democratização.

\section{Introdução}

A Constituição Federal está comemorando 21 anos. É ainda muito jovem se comparada a outras de outros países. Porém, tem marcas bastante fortes para um tempo tão curto de vida. Dezenas de emendas quase Ihe deram outro rosto. Mas ela está ai. Resiste. E, para que continue resistindo, o controle da constitucionalidade das leis e atos normativos é fundamental.

Não será abordada neste trabalho a questão sobre o verdadeiro "guardião da constituição". Porém, parece importante salientar que a legitimidade democrática do Judiciário para o controle da constitucionalidade não é unânime. Para Jürgen Habermas, a existência de tribunais constitucionais não é auto evidente e mesmo em países que o possuem - 0 autor se refere à Alemanha e EUA - sua posição na ordem constitucional e a legitimidade de suas decisões são assuntos controvertidos. E acrescenta: mesmo que, em

\footnotetext{
${ }^{1}$ Bacharel em Direito pela Universidade Estadual de Londrina e advogado

${ }^{2}$ Mestre em Direito Negocial, especialista em Filosofia Política e Jurídica pela Universidade Estadual de Londrina e advogada
} 
última instância, a tarefa do tribunal constitucional seja a de interpretar a constituição e de manter a coerência da ordem jurídica, do ponto de vista da teoria da constituição, a reunião dessas competências em uma única instituição não é absolutamente necessária (HABERM AS, 2005, p. 312).

Porém, o fato é que, no Brasil, o controle da constitucionalidade está reservado precipuamente ao Poder Judiciário e a intervenção do amicus curiae nesses processos pode contribuir para a democratização e legitimação das decisões que deles resultam. É o que será apresentado.

\section{Controle da constitucionalidade}

0 controle da constitucionalidade ${ }^{3}$ das normas jurídicas está sujeito a, pelo menos, dois pressupostos: supremacia e rigidez constitucional.

Por supremacia das normas constitucionais deve-se entender que tais normas são superiores em relação a todas as demais normas jurídicas, ou seja, há um escalonamento entre as normas jurídicas no qual a constituição ocupa o ponto mais alto. Em outras palavras, a constituição condiciona todo o sistema jurídico, tem o máximo de eficácia, e atua como padrão jurídico fundamental para todas as outras normas, não sendo admissível a existência, no Estado, de normas que concorram com ela ou the sejam hierarquicamente superiores (DALLARI, 1995, p. 203).

De nada adiantaria falar em supremacia das normas constitucionais se o legislador pudesse alterá-las no exercício de sua função ordinária. A supremacia das normas constitucionais não teria valor algum se elas pudessem ser alteradas sem um mínimo de dificuldade em relação à produção das demais normas jurídicas ou mesmo que estas últimas pudessem alterar a constituição. Diante dessa impossibilidade, fala-se em rigidez constitucional.

\footnotetext{
${ }^{3} 0$ controle da constitucionalidade nasceu nos EUA. "Em verdade, a Constituição dos Estados Unidos não faz menção expressa a um controle de constitucionalidade das leis deferidas aos seus tribunais. Como não faz também nenhuma menção ao princípio da separação dos poderes. Isto, todavia, não foi obstáculo a que Marshall, valendo-se de impecável lógica, demonstrasse no célebre aresto da questão "Marbury vs. Madison" que o princípio das Constituições rígidas impõe necessariamente aquela supremacia" (ou a constituição é lei superior e suprema, que se não pode alterar por vias ordinárias, ou entra na mesma esfera e categoria dos atos legislativos ordinários, sendo como tal suscetível também de modificar-se ao arbítrio da legislatura). BONAVIDES, 2004, p. 306.
} 


\section{"Amicus curiae": democratização e legitimação do processo decisório de controle da constitucionalidade}

Considerando-se supremacia e rigidez constitucionais, percebe-se que haverá a necessidade de verificar, em determinados casos, se há ou não adequação das normas infraconstitucionais ao que determina a Constituição. É o controle da constitucionalidade que, no Brasil, é realizado precipuamente pelo Judiciário, como já afirmado.

O controle da constitucionalidade pode ser exercido preventivamente, ou seja, antes que a norma ingresse no ordenamento jurídico, e repressivamente, buscando repelir do ordenamento jurídico a norma contrária à constituição, seja pela não-observação dos requisitos formais, relacionados ao processo de elaboração das normas jurídicas, seja pela contrariedade aos requisitos materiais, referentes ao conteúdo das normas. No primeiro caso ocorre durante o processo legislativo de formação do ato normativo. É realizado pelo Legislativo, através da atuação das comissões permanentes de constituição e justiça (artigo 58/CF e Regimentos Internos) e pelo plenário das casas. 0 Executivo o exerce por meio do poder de veto (artigo 66 § 1/CF) e o Judiciário, quando existir, por exemplo, vedação ao próprio trâmite da espécie normativa na Constituição Federal ${ }^{4}$. No segundo caso, em regra, é exercido pelo Poder Judiciário, pela via difusa ou concentrada, como se verá adiante. Há, ainda, hipóteses em que 0 Poder Legislativo realiza o controle posterior de constitucionalidade: a)sustando os atos normativos do Poder Executivo que exorbitem do poder regulamentar ou dos limites de delegação legislativa (artigo 49, V/CF); b) rejeitando medida provisória inconstitucional (artigo $62 \S 50 / \mathrm{CF})^{5}$

0 que mais interessa neste trabalho é o controle repressivo realizado pelo Judiciário que pode ocorrer através de dois sistemas. 0 primeiro - por via de ação - é denominado reservado ou concentrado. 0 segundo - por via de exceção ou defesa - denomina-se difuso ou aberto. Este último é realizado por qualquer juiz ou tribunal diante de um caso concreto

\footnotetext{
${ }^{4}$ Busca-se, no controle preventivo de constitucionalidade pelo Poder Judiciário, a garantia ao parlamentar do devido processo legislativo, vedando a sua participação em procedimento contrário às regras constitucionais. Neste particular, o controle é efetuado pela via de exceção, em defesa de direito de parlamentar, sendo consolidada a jurisprudência no STF no sentido de negar legitimidade ativa àqueles que não sejam parlamentares, sob pena de transformação em controle preventivo de constitucionalidade em abstrato, inexistente no sistema constitucional brasileiro (vide STF: MS 24667/DF, MS 20257/DF, MS 21642/DF, MS 21303-AgR/DF, MS 24356/DF). LENZA, 2009, p. 167.

${ }^{5}$ Sobre a possibilidade de controle repressivo de constitucionalidade pelo Poder Executivo, o STJ (REsp 23121/GO) e o STF (ADIMC 221/DF) já decidiram que este pode (STF), ou possui o dever (ST)), de negar execução a ato normativo que considere inconstitucional. No entanto, ambas as Cortes não se aprofundaram no assunto. Há que se consignar, ainda, a possibilidade de apreciação da constitucionalidade - no caso concreto - pelo Tribunal de Contas da União, que pode inclusive sustar atos que considerar inconstitucionais (artigo 71, X/CF), conforme expresso na Súmula 347 do STF: "o Tribunal de Contas, no exercício de suas atribuições, pode apreciar a constitucionalidade das leis e dos atos do Poder Público". LENZA, 2009, p. 174.
} 
como questão prejudicial e pressuposto para análise do pedido principal. Ocorre quando uma das partes alega em sua defesa a inconstitucionalidade de lei que lhe está sendo aplicada.

Por sua vez, o controle concentrado da constitucionalidade das normas jurídicas é efetuado através da interposição de ação específica por titulares designados constitucionalmente e diretamente ao Supremo Tribunal Federal. Visa à declaração de inconstitucionalidade da lei ou ato normativo em tese, ou seja, independentemente da existência de um caso concreto. É possível em diversas situações: a) ação direta de inconstitucionalidade genérica (artigo 102, I "a" primeira parte/CF); b) ação declaratória de constitucionalidade (artigo 102, I "a" segunda parte /CF); c) ação direta de inconstitucionalidade interventiva (artigo 36, III/CF); d) ação direta de inconstitucionalidade por omissão (artigo 103 §2 /CF); e) arguição de descumprimento de preceito fundamental (artigo $102 \S 1$ 으).

Desde a promulgação da Constituição em 1988, o controle de constitucionalidade das leis e atos normativos sofreu diversas alterações e regulamentações legislativas, sendo possível destacar:

1 - EC 03/1993: a) possibilitou propositura de ação declaratória de constitucionalidade; b) ampliou o rol dos legitimados a propor ação direta de inconstitucionalidade através de alteração dos artigos 101 e 103 /CF;

2 - Lei ordinária 9.868/99: a) regulamentou os processos e julgamentos da ação direta de inconstitucionalidade, inclusive por omissão e declaratória de constitucionalidade; b) alterou dispositivos do Código de Processo Civil (artigo 482 §§ 1ํa 3으);

3 - Lei ordinária 9.882/99: a) regulamentou os processos e julgamentos de arguição de descumprimento de preceito fundamental;

4 - EC 45/2004: a) estabeleceu a necessidade de demonstração da "repercussão geral" das questões constitucionais discutidas no controle difuso (§3ำ artigo 102 CF); b) possibilitou a edição, revisão e cancelamento de súmula vinculante aprovada pelo STF;

5 - Lei ordinária 11.417/06: disciplinou a edição, revisão e o cancelamento de enunciado de súmula vinculante pelo Supremo Tribunal Federal;

6 - Lei ordinária 11.418/06: a) regulamentou 0 §3ํ do artigo 102 da CF através do acréscimo dos artigos 543-A e 543-B ao Código de Processo Civil. 


\section{"Amicus curiae": democratização e legitimação do processo decisório de controle da constitucionalidade}

0 debate jurisprudencial no controle da constitucionalidade também deve ser considerado. Em relação ao tema deste estudo devem ser analisadas, especialmente, as reflexões a respeito da possibilidade da intervenção do amicus curiae no processo de controle por via de exceção.

A partir de uma análise prévia das alterações acima citadas, já é possível afirmar que o controle de constitucionalidade vem passando por um processo de democratização que culminou com a possibilidade de participação do amicus curiae no controle da constitucionalidade por via de exceção, como adiante será exposto.

\section{Amicus Curiae}

A instituição amicus curiae desenvolveu-se nos Estados Unidos da América (Rule 37) e está associada ao controle da constitucionalidade, embora suas origens remontem ao direito romano, onde tinha a função de ser um colaborador neutro do magistrado quando a resolução do caso envolvia questões não estritamente jurídicas. Sua única obrigação era ser leal aos juízes (BUENO, 2006, p. 88).

A expressão latina amicus curiae significa "amigo da cúria". Modernamente é utilizada como "amigo da corte" ou "amigo da justiça", inclusive pelos juristas norteamericanos, que o designam como "friend of the Court". Para a doutrina norte-americana, 0 amicus curiae é uma pessoa que não é parte em um processo judicial, mas que peticiona à corte ou é convocada por ela para apresentar um parecer em virtude de possuir um forte interesse no assunto em pauta (PEDROLLO, 2005, p. 162).

A doutrina nacional, em regra, não diverge da norte-americana, pois considera 0 amicus curiae um terceiro, porém Ihe acrescenta adjetivos como "enigmático" (BUENO, 2006, p. 419), especial, de natureza excepcional (PEREIRA, 2003, p. 109), desinteressado no sentido jurídico, ou ainda, sui generis, que pratica intervenção atípica no processo alheio, para diferenciá-lo das figuras arroladas no Código de Processo Civil. Trata-se, portanto, de terceiro que busca intervir em processo alheio por razões diversas daquelas que motivam a intervenção das figuras conhecidas e tradicionais arroladas pelo Código de Processo Civil.

Em monografia sobre o tema, Cássio Scarpinella Bueno (2006, p. 125) define a figura do amicus curiae como um portador de conhecimento, de opiniões e informações úteis ou indispensáveis que, fornecidas ao magistrado, Ihe conferem o que 0 autor 
denomina de "ótimas condições" ao julgamento de uma determinada questão, de forma a melhor realizar a tarefa da hermenêutica jurídica. 0 amicus curiae não possui um interesse jurídico, entendido como aquele que decorre de uma específica relação jurídica-base entre dois ou pouco mais de dois indivíduos, que tem tudo para ser afetada, direta ou indiretamente, atual ou potencialmente, pela decisão a ser proferida num processo. 0 autor fala de um "interesse institucional" capaz de legitimar a participação do amicus curiae. Trata-se de um interesse jurídico, porém diferenciado,

que não pode ser confundido ou assimilado com o interesse que conduz um 'assistente' ou outro 'terceiro' qualquer a um processo entre outras pessoas para nele intervir das variadas formas que 0 nosso direito, tradicionalmente, Ihe reconhece. Não se trata de um interesse jurídico subjetivado. Mas se trata, com essas ressalvas, de um interesse que é jurídico.

O que legitima sua participação é o direito; é um interesse que decorre do direito e por isso pode ser qualificado de jurídico. Esse é também o entendimento de Cássio Scarpinella Bueno: "é um interesse jurídico porque é previsto, porque é agasalhado, porque é tutelado pela ordem jurídica como um todo".

O interesse jurídico que legitima a intervenção de terceiros regulada pelo Código de Processo Civil é diferente daquele que legitima a intervenção do amicus curiae. No primeiro caso tem-se um interesse jurídico decorrente de uma relação jurídica fundamentada em direito material. No segundo caso, o interesse está em auxiliar a tarefa judicial de interpretar e aplicar as leis. Essa diferença pode até fornecer o critério para a admissão do amicus curiae, pois sua participação não pode servir para permitir o que a lei impede. É o caso, por exemplo, da Lei $9.868 / 00$ que não permite, nos processos de ação direta de inconstitucionalidade e declaratória de constitucionalidade, a intervenção de terceiros disciplinada pelo Código de Processo Civil, porém admite o amicus curiae

No Acórdão da ADIn n 2321/DF ${ }^{6}$, julgada em 25/10/2000, o STF fez referência ao amicus curiae como um terceiro admitido na relação processual para efeito de manifestação sobre a questão de direito subjacente à própria controvérsia constitucional, permitindo que o Tribunal disponha de todos os elementos informativos possíveis e necessários à resolução da controvérsia.

\footnotetext{
${ }^{6}$ Disponível em: «www.stf.jus.br>. Acesso em: 13 maio 2007
} 


\section{O Amicus Curiae no processo de controle da constitucionalidade}

O surgimento da figura do amicus curiae no direito brasileiro ocorreu com a lei 6.385/1976 alterada pela lei 6.616/1978 que prevê a participação da Comissão de Valores Mobiliários em processos nos quais se discutem questões de direito societário.

No controle da constitucionalidade, as primeiras discussões acerca do amicus curiae surgiram no Supremo Tribunal Federal em meados da década de 1990, no julgamento do Agravo Regimental na ADIn (ação direta de inconstitucionalidade) $n^{\circ} 748$, ocorrido em 01.08.1994, quando ainda não havia previsão normativa acerca da participação do amicus curiae (PEDROLLO, 2005, p. 167). Tal ação, ajuizada pelo então governador do Estado do Rio Grande do Sul, objetivava a declaração de inconstitucionalidade de um decreto legislativo editado pela Assembléia Legislativa daquele estado. Anteriormente ao julgamento da ação, o relator determinou a juntada de expediente encaminhado pela Assembléia, apensado aos autos, relativo a estudos técnicos e pareceres a respeito da matéria atingida pelo decreto em discussão. No agravo, que discutia a juntada do referido expediente, foi decidido que não havia ocorrido a admissão do órgão legislativo no processo como terceiro interveniente nem Ihe havia dado acesso ao processo de controle concentrado de constitucionalidade. $\mathrm{Na}$ verdade, como proferido no voto do ministro, a Assembléia Legislativa atuou como verdadeiro amicus curiae, fornecendo peças documentais destinadas a esclarecer repercussões que a decisão poderia ocasionar ${ }^{7}$.

Através da lei 9.868/99, foi consagrada a atuação do amicus curiae no processo de controle da constitucionalidade. A referida lei, como já mencionado, proíbe a intervenção de terceiros (artigo 7은 nos processos e julgamentos que regula (ADIn e ADECON), porém, no caso da ação direta de inconstitucionalidade, considerando a relevância da matéria em discussão e a representatividade dos postulantes, admite a manifestação de outros órgãos ou entidades ( $\$ 20$ do artigo 7ํ). Não utiliza a expressão amicus curiae, mas não restam dúvidas de que se trata dessa figura, como já se manifestou o Supremo Tribunal Federal. Entre tais manifestações é possível destacar a exposição sobre o tema feita, em 2005, pelo ministro Gilmar Ferreira Mendes em decisão que, com fundamento no artigo $\S 2^{\circ}$ do $7^{\circ}$ da

7 STF.AgR na ADIn n 748/RS. Julg. Em 01.08.1994. Disponível em: «www.stf.jus.br>. Acesso em: 13 maio 2007. 
Lei 9.868/99, deferiu pedido de intervenção como amicus curiae da Federação das Indústrias do Estado do Paraná - Fiep:

A constatação de que, no processo de controle de constitucionalidade, se faz, necessária e inevitavelmente, a verificação de fatos e prognoses legislativos, sugere a necessidade de adoção de um modelo procedimental que outorgue ao Tribunal as condições necessárias para proceder a essa aferição.

Esse modelo pressupõe não só a possibilidade de o Tribunal se valer de todos os elementos técnicos disponíveis para a apreciação da legitimidade do ato questionado, mas também um amplo direito de participação por parte de terceiros (des)interessados.

[...] Entendo, portanto, que a admissão de amicus curiae confere ao processo um colorido diferenciado, emprestando-Ihe caráter pluralista e aberto, fundamental para o reconhecimento de direitos e a realização de garantias constitucionais em um Estado Democrático de Direito ${ }^{8}$.

A Lei 9.868/99 não prevê a intervenção de amicus cúria para o caso de ação direta de constitucionalidade, ficando apenas vedada a intervenção de terceiros (artigo 18). 0 legislador ordinário (Lei 9.882/99) também não fez tal previsão para os processos e julgamentos da arguição de descumprimento de preceito fundamental como fez no caso da ação direta de inconstitucionalidade. Porém, nos três casos (ação direta de inconstitucionalidade, ação declaratória de constitucionalidade e arguição de descumprimento de preceito fundamental), possibilitou ao relator "requisitar informações adicionais, designar perito ou comissão de peritos para que emita parecer sobre a questão ou fixar data para, em audiência pública, ouvir depoimentos de pessoas com experiência e autoridade na matéria." (§10 do artigo 90 e §10 do artigo 20 da Lei 9.868/99 e § 10 do artigo 6 o da Lei 9882/99). Não há, dessa forma, empecilho para intervenção no amicus curiae nesses três casos e o Supremo Tribunal Federal vem-se posicionando favoravelmente à admissão do amicus curiae tanto na Arguição de Descumprimento de Preceito Fundamental como na Ação Declaratória de Constitucionalidade ${ }^{9}$. Conforme explica Cássio Scapinella Bueno (2006, p. 176),

\footnotetext{
${ }^{8}$ STF, ADIn/2548, Disponível em: «www.stf.jus.br>. Acesso em 05 out. 2009.

${ }^{9}$ É o que se pode confirmar nas recentes decisões:

Trata-se de arguição de descumprimento de preceito fundamental, ajuizada pelo Partido da Social Democracia Brasileira - PSDB, com pedido de concessão de medida cautelar inaudita altera parte, objetivando conferir interpretação conforme a Constituição ao art. 224 do Código Eleitoral, de maneira que, seja qual for o motivo da nulidade e, independentemente de a eleição ter ocorrido em dois turnos, se a maioria dos votos for de sufrágios nulos, impõe-se a convocação de nova eleição. Às fls. 328-531, o Partido Verde - PV requer seu ingresso na presente ADPF na condição de amicus curiae. É o breve relatório. Decido.
} 


\section{"Amicus curiae": democratização e legitimação do processo decisório de controle da constitucionalidade}

A utilidade da intervenção do amicus curiae deriva muito mais do próprio sistema constitucional e de um novo paradigma de interpretação, compreensão e sistematização do direito do que propriamente, do texto (expresso) da lei.

A Emenda Constitucional $n^{\circ} 45$ de 2004 instituiu no sistema jurídico brasileiro a possibilidade de edição de súmula vinculante pelo Supremo Tribunal Federal de ofício ou por provocação, mediante decisão de dois terços dos seus membros, depois de reiteradas decisões sobre matéria constitucional. 0 efeito vinculante estende-se aos demais órgãos do Poder Judiciário, administração pública direta e indireta - nas esferas federal, estadual e municipal - podendo ainda o Supremo Tribunal Federal revisá-las e cancelá-las de acordo com a regulamentação estabelecida pela Lei 11.417/2006. Este diploma legal, em seu artigo 3ำ $2^{\circ}$, também possibilita a intervenção do amicus curiae, porquanto permite ao relator, no procedimento de edição, revisão ou cancelamento de enunciado de súmula vinculante,

Verifico que o pedido foi formulado por agremiação política que atende aos requisitos necessários para participar da presente ação na qualidade de amigo da Corte. Sobre a questão, colho pronunciamento do M in. Celso de M ello, nos autos da ADI 3.045/DF, de sua relatoria: "a intervenção do amicus curiae, para legitimarse, deve apoiar-se em razões que tornem desejável e útil a sua atuação processual na causa, em ordem a proporcionar meios que viabilizem uma adequada resolução do litígio constitucional". Isso posto, defiro 0 pedido, nos termos do art. $6^{\circ}, \S \S 10$ e $2^{\circ}$, da Lei 9.882/1999, observando-se, quanto à sustentação oral, 0 disposto no art. 131, § 3o, do RISTF, na redação dada pela Emenda Regimental 15/2004. À Secretaria, para registro da agremiação. Publique-se. Brasília, 15 de setembro de 2009. Ministro RICARDO LEWANDOWSKI Relator (ADPF 155 / PB, Relator(a): M in. RICARDO LEWANDOWSKI, julgado em 15/09/2009, DJe-177 DIVULG 18/09/2009 PUBLIC 21/09/2009)

DECISÃO, AÇÃO DECLARATÓRIA DE CONSTITUCIONALIDADE. INTERVENÇÃO DE TERCEIRO, CONSELHO FEDERAL DA ORDEM DOS ADVOGADOS DO BRASIL, ADM ISSIBILIDADE. 1. Eis as informações prestadas pelo Gabinete: 0 Conselho Federal da Ordem dos Advogados do Brasil requer seja admitido, na qualidade de amicus curiae, no processo em referência, ante a relevância da matéria ' discussão da Lei Maria da Penha ' e a respectiva representatividade. Alega que a Ordem dos Advogados do Brasil tem tradição na defesa da Constituição, dos direitos humanos e da justiça social, tratando-se, inclusive, de competência legal (artigo 44, inciso I, da Lei no 8.906/94 ' Estatuto da Ordem). Caso seja admitida a intervenção, pleiteia seja-lhe concedido prazo para o oferecimento de manifestação e assegurado o direito de pronunciamento oportuno no transcorrer do processo, bem como de promover sustentação oral. 0 processo está na Procuradoria Geral da República. 2. Embora 0 artigo 70 da Lei no 9.868/99 refira-se à ação direta de inconstitucionalidade, entendo-o aplicável à declaratória de constitucionalidade prevista na mesma lei. É que ambas são de mão dupla, podendo-se chegar quer à conclusão sobre a harmonia do ato normativo com a Carta Federal, quer a resultado diverso, assentando-se a pecha. No mais, reconheço ao Conselho Federal da Ordem dos Advogados do Brasil papel em defesa da própria sociedade. Então, em jogo a denominada Lei Maria da Penha ' Lei no 11.340/2006 ', tenho como acolhível o pleito formalizado. Sob o ângulo da abertura de prazo para oferecimento de manifestação, observem a organicidade do Direito, especialmente do instrumental. Indeferida a medida acauteladora, o processo seguiu à Procuradoria Geral da República para emissão de parecer. 0 Conselho Federal da Ordem dos Advogados do Brasil, como terceiro, recebe-o no estágio em que se encontra. Quanto à sustentação oral, deve-se acompanhar a inclusão do processo em pauta, publicada no Diário da Justiça, e a veiculação, no sítio do Tribunal, da notícia relativa ao julgamento a ser realizado. 3. Publiquem. Braślia, 6 de outubro de 2008. Ministro MARCO AURÉLIO Relator (ADC 19, Relator(a): Min. MARCO AURÉLIO, julgado em 06/10/2008, DJe-195 DIVULG 14/10/2008 PUBLC 15/10/2008).

Disponível em: «www.stf.jus.br>. Acesso em: 05 out.2009.

ReVISTA de DiReITo Público, LondRINA, V, 4, N. 3, P. 37-49, SET/ DEZ. 2009. 
"admitir, por decisão irrecorrível, a manifestação de terceiros na questão, nos termos do Regimento Interno do Supremo Tribunal Federal".

Tratou-se até aqui da intervenção do amicus curiae no controle concentrado de constitucionalidade. No controle difuso, o legislador ordinário previu - através da Lei 9.868/99 - para os casos de arguição de inconstitucionalidade nos tribunais (artigo 480,§ § 2ำ e 3 ㅇ CPC), a possibilidade de manifestação dos titulares do direito de propositura de ação direta (artigo 103/CF), e também a possibilidade do relator, considerando a relevância da matéria e a representatividade dos postulantes, admitir, por despacho irrecorrível, a manifestação de outros órgãos ou entidades (artigo 482, §3ㅇ CPC) sobre a questão constitucional objeto de apreciação pelo órgão especial ou pelo Pleno do Tribunal. Está aí, portanto, previsão legal para a intervenção do amicus curiae ${ }^{10}$ no controle difuso. É possível afirmar, portanto, que, as alterações no Código de Processo Civil efetuadas pela Lei 9.868/99, "de alguma forma levam àquele incidente algumas das mesmas características do controle concentrado de constitucionalidade, vale dizer, a possibilidade de ser franqueada maior discussão quanto à constitucionalidade da norma por ocasião de seu julgamento. (...) Trata-se, pois, de mais uma hipótese em que, expressamente, o direito brasileiro consagrou a figura do amicus curiae, embora não tenha, também aqui, empregado esse nome" (BUENO, 2006, p. 190).

Ainda em relação ao controle difuso, deve-se destacar que cabe ao Supremo Tribunal Federal (artigo 102, III /CF) julgar, mediante recurso extraordinário, as causas decididas em única ou última instância, quando a decisão recorrida - entre outras hipóteses contrariar dispositivo da Constituição e declarar a inconstitucionalidade de tratado ou lei federal. A mesma emenda constitucional referida acima (45/2004) acrescentou ao artigo 102,III /CF o § 3o exigindo assim a demonstração de "repercussão geral das questões constitucionais" como requisito para admissibilidade do recurso extraordinário. A Lei 11.418/06 disciplinou a matéria acrescentando ao Código de Processo Civil os artigos 543-A e 543-B e no §60 do primeiro deles, fez referência à possibilidade de intervenção do amicus curiae na análise da presença do referido requisito de admissibilidade (BUENO, 2006, p. 190).

\footnotetext{
${ }^{10}$ A Lei 10. 259/2001 possui previsão semelhante para a uniformização de jurisprudência nos casos de competência dos Juizados especiais cíveis e criminais no âmbito da Justiça Federal (artigo 14 § 7ํ).
} 


\section{"Amicus curiae": democratização e legitimação do processo decisório de controle da constitucionalidade}

Em todos os casos de intervenção do amicus curiae no processo de controle de constitucionalidade por via de ação ou exceção, deve o interveniente cumprir sua primordial função de "auxiliar a corte" através da juntada aos autos de informações que possam contribuir para a interpretação do texto constitucional, inclusive apresentando os possíveis reflexos produzidos pela eventual decisão da corte. A interpretação constitucional não é um evento exclusivamente estatal. Vem deixando de ser vinculada a uma sociedade fechada, da qual tomam parte apenas os intérpretes jurídicos participantes formais do processo de controle constitucional. É uma atividade que diz respeito a todos, e à qual todas as forças da comunidade devem ter acesso. Todos os que vivem no contexto regulado por uma norma são, direta ou indiretamente, intérpretes da norma (HÄBERLE, 2002, p. 23).

Todavia, a intervenção do amicus curiae no controle de constitucionalidade por via de exceção não deve deixar de se apresentar sobre os contornos que the são peculiares, ou seja, a relevância da matéria e a representatividade dos postulantes ${ }^{11}$. Ainda: sua intervenção limita-se a discutir a constitucionalidade da lei a ser aplicada ao caso. Como já se disse, neste trabalho, seu interesse é institucional, é auxiliar a corte para que a decisão tomada sobre a constitucionalidade de lei ou de atos normativos derive de um

11 Sobre a possibilidade de intervenção do amicus curiae no controle difuso de constitucionalidade, no entanto, a jurisprudência é divergente. Como exemplo, em processos que discutem a vigência de patente de medicamentos, 0 Tribunal Regional Federal da 2 a Região já se posicionou a favor e contra a admissão do amicus curiae.

No agravo interno no 2007.02.01.006831-6, julgado em 28.02.2008, que discutia justamente o deferimento do ingresso do amicus curiae no processo principal, o agravante, empresa farmacêutica ré na lide principal, requereu a reconsideração da decisão que deferiu o ingresso como amicus curiae de Associação Brasileira de Indústrias Afetas ao Ramo da Biotecnologia, sob o argumento de que as associadas eram suas concorrentes, e que pretendiam explorar o objeto da patente, evidenciando interesse meramente econômico, além de prejudicar a celeridade do feito. Em seu voto, o relator do Agravo afirmou que, embora a entidade admitida como amicus curiae represente as indústrias atuantes no ramo farmacêutico, é de interesse de toda a sociedade que não subsista a exclusividade sobre a exploração de determinado invento, com a revalidação de patente estrangeira de medicamento. Não deveria ser exigida imparcialidade do amicus, pois o objetivo de sua admissão é meramente fornecer elementos informativos ao julgador sobre questão de grande repercussão so cial, como o caso dos autos. Ademais, a garantia de razoável duração do processo não seria capaz de impor óbice à melhor compreensão, pelo Tribunal, acerca dos fatos a serem analisados. Dessa forma, foi negado provimento ao agravo.

Por outro lado, em questão semelhante, apresentada na Apelação em Mandado de Segurança no 2005.51.01.507058-6, julgada em 09.09.2008, discutiu-se a admissão de associação representativa de associação em processo que discutia a vigência de patente de um medicamento, sendo indeferida a participação do amicus curiae, pois: a) se vislumbrava mero interesse econômico, o que afrontava o entendimento jurisprudencial histórico que não 0 admitia; b) a admissão de grupos de interesse ou pressão ameaçaria o desequilíbrio entre as partes; c) a aceitação da intervenção de diversos amici curiae iria inviabilizar a duração razoável do processo; d) apenas de forma aparente as entidades contribuem para 0 esclarecimento dos fatos, apresentando, na verdade, argumentos comprometidos com os grupos sociais e econômicos que representam.

ReVIsta de Direito PúBLICO, LONDRINA, V, 4, N. 3, P. 37-49, SET/ DEZ. 2009. 
procedimento mais democrático, mais plural e por isso mais legítimo. Deve o amicus curiae prestar informações, subsídios para melhor análise pelos tribunais de questões relevantes cujos efeitos podem repercutir por toda sociedade. Interesses subjetivos do interveniente devem ser defendidos exclusivamente através dos modelos tradicionais de intervenção previstos pelo Código de Processo Civil. Repita-se ainda: seu interesse, também nesses casos, é institucional, é auxiliar a corte para que a decisão tomada sobre a constitucionalidade de lei ou de atos normativos derive de um procedimento mais democrático, mais plural e por isso mais legítimo.

Acrescente-se que são cada vez mais frequentes os litígios cuja especificidade e tecnicidade exigem dos juízes conhecimentos que Ihes são alheios. Tais peculiaridades estão presentes não apenas nos processos objetivos, mas também nos subjetivos. A intervenção do amicus curiae no processo, trazendo, inclusive, elementos externos ao direito, como, por exemplo, argumentos econômicos e sociológicos, auxiliam o juiz à melhor compreensão das questões que the são colocadas e à melhor avaliação das consequências sociais de sua decisão $0^{12}$.

Mais importante ainda: a constante referência a princípios para solução de problemas jurídicos numa sociedade que se tornou complexa e plural, na qual a referência às tradições ou a uma ordem sacra não é mais capaz de fornecer os elos que unem suas estruturas, aumenta a importância dos procedimentos para legitimação das decisões estatais sejam elas judiciais ou legislativas e administrativas. Portanto, a intervenção do amicus curiae no processo - objetivo ou mesmo subjetivo - coaduna-se com a idéia de processo e procedimentos (GUERRA FILHO, 2001, p. 64) que - regulados pelo direito - são, como explica Willis Santiago Guerra Filho, "o método empregado na formação da 'vontade estatal' em um Estado de Direito".

12 Não é aqui o lugar para discutir os poderes e deveres atribuídos ao juiz. Porém, é bom acrescentar que 0 juiz do estado liberal preocupado apenas com a liberdade dos cidadãos, que era tão somente 0 árbitro de um jogo entre autor e réu não pode mais existir. 0 juiz do estado democrático de direito participa do processo, inclusive, podendo determinar que terceiros venham trazer informações e posicionamentos a respeito da questão discutida. 


\section{Conclusão}

A intervenção do amicus curiae nos processos de controle da constitucionalidade põe luz num caminho que leva à procedimentalização da formação da vontade estatal no âmbito do Poder Judiciário colaborando para a legitimação democrática de suas decisões.

\section{Referências}

BONAVIDES, Paulo. 0 controle da constitucionalidade. In: Curso de direito constitucional. 14. ed. São Paulo: M alheiros, 2004.

BUENO, Cassio Sacapinella. Amicus curiae no processo civil brasileiro: um terceiro enigmático. São Paulo: Saraiva, 2006.

DALLARI, Dalmo de Abreu. Elementos de teoria geral do Estado. 1995. 203 p.

GUERRA FILHO, Willis Santiago. A Filosofia do direito: aplicada ao Direito Processual e à Teoria da constituição. São Paulo: Atlas, 2001.

HÄBERLE, Peter. Hermenêutica Constitucional. A sociedade aberta dos intérpretes da constituição: contribuição para a interpretação pluralista e "procedimental" da constituição. Tradução de Gilmar Ferreira M endes. Porto Alegre: Sergio Antonio Fabris Editor, 2002.

HABERM AS, Jürgen. Facticidad y validez: Sobre el derecho y el Estado democrático de derecho en términos de teoría del discurso. Introdução e tradução de Manuel Jiménez Redondo. 4. ed. Madrid: Editorial Trotta, 2005.

LENZA, Pedro. Direito constitucional esquematizado. 13. ed. São Paulo: Saraiva, 2009.

PEDROLLO, Gustavo Fontana. Amicus curiae: elemento de participação política nas decisões judiciais-constitucionais. Revista da Ajuris: doutrina e jurisprudências, Porto Alegre,v. 32, n. 99, set. 2005.

PEREIRA, Milton Luiz. Amicus curiae: Intervenção de terceiros. Revista de processo, São Paulo, v. 28, n. 109, jan./mar. 2003. 